\title{
Job title as an indicator for strategic orientation of the IT Organization?
}

\author{
Bjarne Erik Roscher ${ }^{1,2,3, *}$ \\ ${ }^{1}$ Department of Business, Management and Economics, University of Latvia, Riga, Latvia \\ ${ }^{2}$ FOM Hochschule für Oekonomie \& Management, Department Nürnberg, Essen, Germany \\ ${ }^{3}$ Nuremberg Institute of Technology Georg Simon Ohm, Germany
}

\begin{abstract}
.
Companies are more and more dependent on information technology (IT) and the buzzword digitization is present everywhere. Some companies are inventing new business models based on disruptive innovation supported by information technology. Others adapt these business models as followers. All these new business processes and underlying information technology need to be managed, serviced, and supported by IT organizations to ensure business continuity. On the other side software and cloud providers have launched applications which in some cases are easy to configure and need a minimum effort to install, connect and maintain. Traditionally heads of the IT department have been fully responsible for all aspects of IT usage in the company - including IT cost, IT governance, IT \& process planning and implementation and IT operation. The change of technology offerings by externals results in a need to focus on strategic tasks like strategy and roadmap planning, IT governance, IT budgeting and enterprise architecture management (EAM). This results in the fact that there is a need of more intensive Business-IT alignment to ensure that IT architecture of a company supports the business processes at its best and to ensure the economic value contribution of IT as a hole. This research investigates the influence of several variables (strategic IT management tasks, reporting structure, leadership experience and the personality trait of being a "Hands-on" person) on Job titles. Empirical data suggest that the Job title of a Chief Information Officer (CIO) is associated with Leadership experience, Hands on mentality and deep knowledge on the topic of IT Architecture. In contrary IT Managers seem to be less strategic but utilitarian.
\end{abstract}

Keywords: Chief Information Officer (CIO), Strategic work tasks, Job title, Recruitment, CIO Role

\subsection{Role and taks of IT Managers}

Synnott defined 1981 the role of the chief information officer (CIO) as the "senior executive responsible for establishing corporate information policy, standards, and management control over all corporate information resources" (Synnott and Gruber 1981).

Many studies have shown that the role of a CIO is essential for an organization: 


\title{
$11^{\text {th }}$ International Conference on Modern Research in
} MANAGEMENT, ECONOMICS and ACCOUNTING

\author{
18-20 December, 2020 Oxford, United Kingdom
}

A CIO can positively influence the company performance not only by fostering the IT efficiency, which means lowering cost and by this increase the profit, yet increase the IT effectivity through improved IT use (Durst 2007).

Measures to drive IT efficiency are introducing tailored internal IT management systems (Schweda and Schmidt 2014), efficient IT service management [ITSM] frameworks (Marrone and Kolbe 2011) and the right organizational setup (Hodgkinson 1992). An efficient budgeting and controlling process which ensures that investments in technology deliver the planned results (Chan et al. 2006) is essential. Measures to improve IT effectivity are supporting business processes with appropriate information technology (Tallon 2014).

But ultimately a CIOs main task is to ensure "Business-IT-Alignment" (BITA). This results in strategic information technology initiatives driving business performance (Peppard 2010). External and internal influences which cause a change of Business Model or Company Strategy, must be captured and incorporated into IT strategy. (Ward and Peppard 2002)

Research has widely discussed the importance of the relationship between CEO and CIO (Chen and Preston 2007; Jones et al. 1995; Krotov 2015; Benlian and Haffke 2016; Feeny et al. 1992) and the importance of the CIO being member of the TMT (Ling et al. 2015; Lee et al. 2014; Georgakakis et al. 2019). Also the area of alignment between CIO and other TMT Managers has been investigated (Whitler et al. 2017; Taylor and Vithayathil 2018)..

Lastly Enterprise Architecture (also called IT Architecture in some literature) drives IT value, which can be achieved through IT effectivity and IT efficiency. Instruments are modelling, management and control of the application landscape and its underlaying IT infrastructure to ensure positive effect on the Business Processes of an organization (Leser et al. 2004; Liu 2002).

Even so literature talks in many cases of Chief Information Officers as the person who is responsible for overseeing and managing the complex topic of IT in an organization the reality regarding his job title and the orientation of his role can vary across industry sectors, countries, organizations size and history (Peppard 2010; Gottschalk and Taylor 2000).

This research investigates if there is a link between certain variables from job ads and the job title awarded by the company to an IT executive.

\subsection{Role of Job titles in literature}

Only few literature in the area of IT discuss job titles or even its impact on outcome of the IT department (Peppard 2010; Gottschalk and Taylor 2000; Li and Tan 2013).

In other areas researchers have found that job titles are important for the coordination in teams due to trust development (Klein et al. 2006; Bechky 2006) and skill differentiation (Hollenbeck et al. 2012).

Banon and Bielby suggest that organizations use job titles to "anchor workers' identities" (Baron and Bielby 1986). Ashforth and Kreiner support that job titles act as "prominent identity badges" (Ashforth and Kreiner 1999). Rafaeli and Pratt describe job titles as artefacts or symbolic objects which sends signals about roles and identities for their social environment (Rafaeli and Pratt 2012). These could be employees, peers, customers, suppliers, the public, 


\section{$11^{\text {th }}$ International Conference on Modern Research in}

MANAGEMENT, ECONOMICS and ACCOUNTING

\section{8-20 December, 2020 Oxford, United Kingdom}

family and friends. Therefore, the author believes that job titles are an important statement to communicate the role and the importance of IT within and outside of the company ecosystem.

\subsection{Hypothesis and Research Question}

Research object:

Job advertisements (also referred to job ads or ads in the paper)

The hypothesis for this research:

Job title is a valid indicator for the strategic orientation of an IT organization.

The research question is:

Is the Job title used in job offerings an indicator for the strategic orientation of the IT organization?

\subsection{Research model}

IT organizations do not act independently in a company but are in a triadic principal agent relationship with the executive Management and other stakeholders on the management level of the company (Vijay Gurbaxani and Chris F. Kemerer 1990). Assuming that, the question arose what variables could be extracted from publicly available IT management job advertisements that are related to these management stakeholders. After literature review the following two have been chosen: Reporting structure, Leadership experience. Additionally, the author picked a variable which is described as Hands-on-personality in several job openings.

Then consequently IT management tasks which have a direct impact on stakeholders in the triadic agent relationship have been identified.

IT Strategy is a process of aligning IT tasks for the following years both with the company strategy and with the business process owners.

IT Architecture planning is the consequence out of the IT Strategy in order to ensure a future oriented IT landscape consisting of IT infrastructure and IT applications. Both infrastructure and applications support and models the business processes and business model.

IT Governance ensures that the IT Architecture principles supporting the IT Strategy are adhered to.

IT Budgeting ensures that the goals defined in the IT Strategy can be reached by having the necessary resources available for planning, designing, introducing, operating and maintaining of the IT Architecture.

All four are closely connected, yet without forward looking budgeting, the first 3 tasks cannot be executed.

Figure 1 shows the relationship between the strategic design dimensions of IT, the stakeholders and the chosen variables from job advertisements. 
$11^{\text {th }}$ International Conference on Modern Research in

MANAGEMENT, ECONOMICS and ACCOUNTING

\section{8-20 December, 2020 Oxford, United Kingdom}

Figure 1. Design Dimensions of IT Organizations with affected stakeholders and variables from job ads.

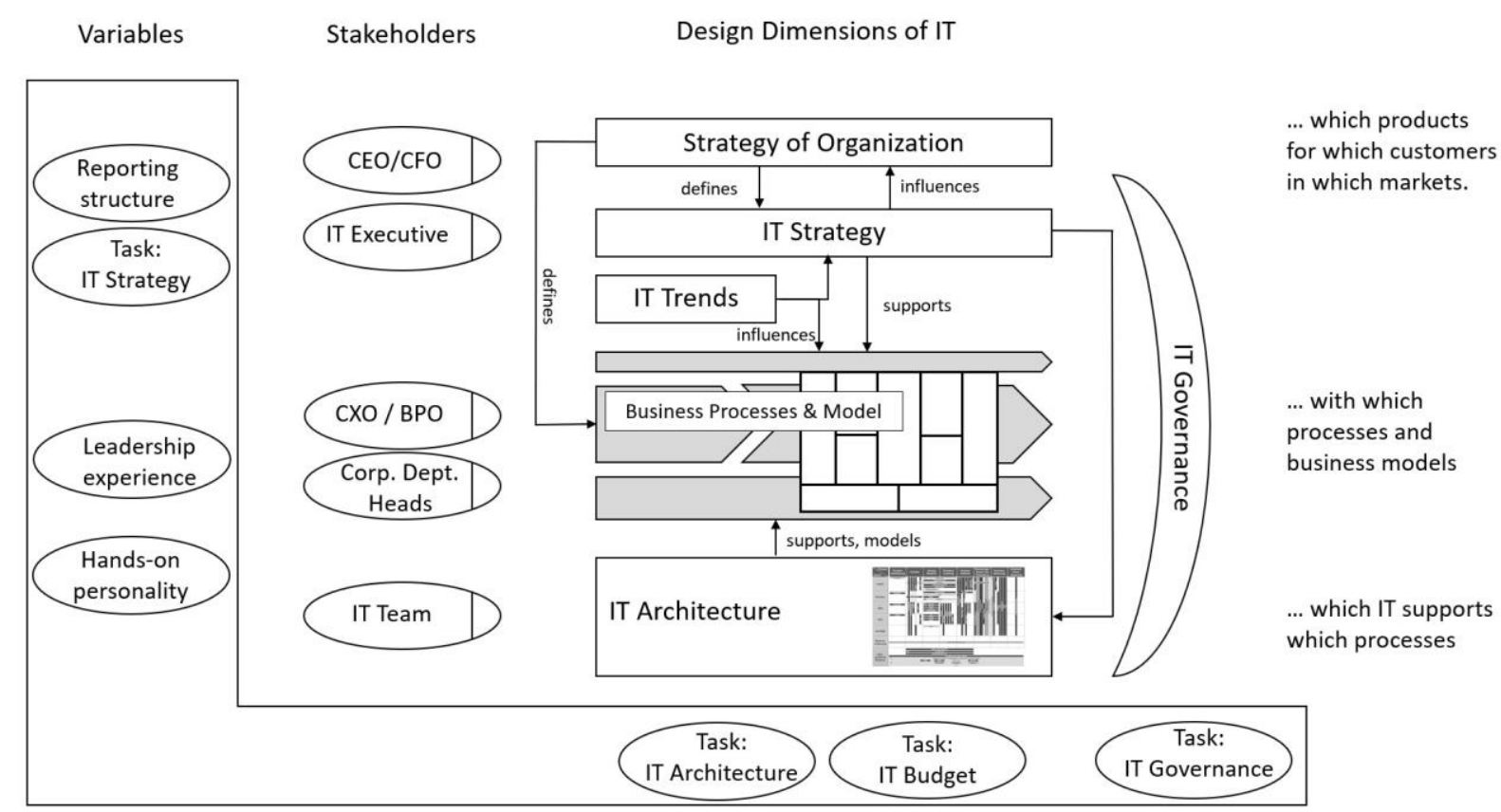

Source: author's construction based on Durst's IT design dimensions (Durst 2007)

\section{Research methodology}

\subsection{Data Collection and selection}

The data collection was carried out on the following dates: a) 18.2.2020, some days before the COVID-19 pandemic started in Germany with all its measures for social distancing $\left(1^{\text {st }}\right.$ wave lockdown) and its impact on business life. b) 28.10 .2020 , right before $2^{\text {nd }}$ wave lockdown. Source for the first dataset (a) has been the internet job portals of indeed.com and linkedin.com. Source for the second dataset (b) was only indeed.com as some manual spot checks on linkedin did not generate more data.

In both cases all available job advertisements on that single day with the search words "IT Manager", "IT Leiter", "Chief Information Officer (CIO)" have been proofread to ensure that they are covering all aspects of an IT manager. In the first dataset the collection process excluded all offerings that had been published by a professional recruiter as these did not contain any information about the employer. In the second dataset these have been collected despite this missing information but later excluded in the data cleansing process executed according the PRISMA-P research methodology (Moher et al. 2015) as shown in Fig. 2. 


\section{$11^{\text {th }}$ International Conference on Modern Research in}

MANAGEMENT, ECONOMICS and ACCOUNTING

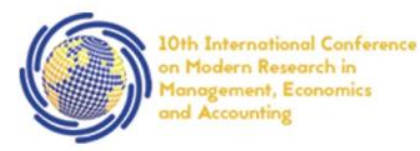

\section{8-20 December, 2020 Oxford, United Kingdom}

Figure 2. Collection and selection process for job advertisement data

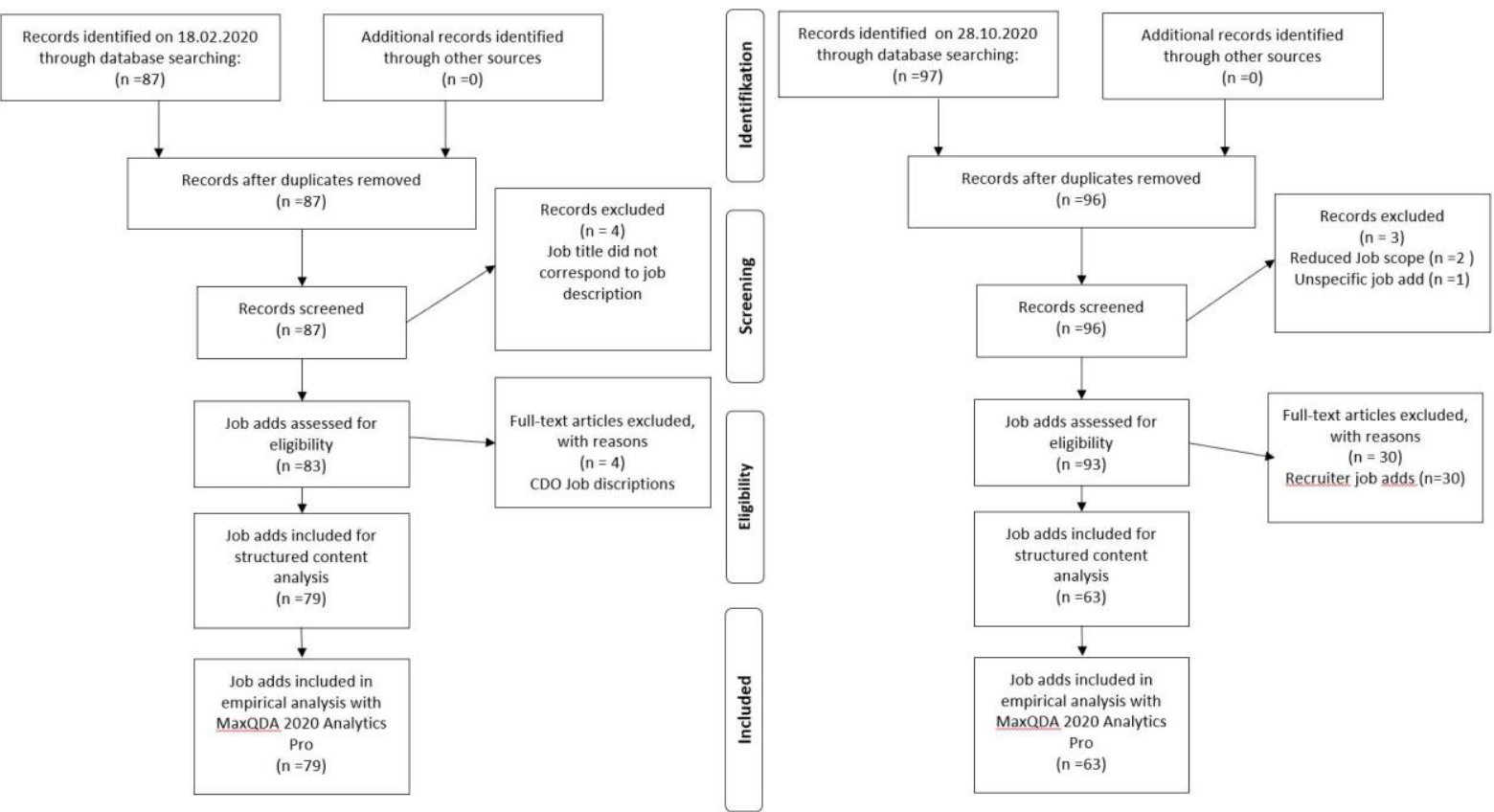

Source: author's construction based on the Prisma-P methodology (Moher et al. 2015)

\subsection{Process of structured text analysis.}

At the beginning of the process tasks, which have been identified as strategic (by analyzing their content and strategic impact (Krcmar 2015; Roscher and Brink 2020)), have been selected. These tasks have been translated to German language and synonyms describing these words identified. As some job offerings have been published in English language only the search phrases had to be translated back and used synchronously with the German phrases. Based on Mayrings method for content analysis, originally published in 1983 (Mayring 2015), the paraphrases have been used searching the documents for sentences surrounding these words. These sentences contained further phrases which have been used to create a wordlist, which then was used for final searching within all job offerings. Finally, all found sentences have been manually read and the decision for inclusion was done due to attributes to the search phrases. Some examples show how decision was made: "Responsible for", "drive" and "contribute" are indicators for inclusion in the result list, "execute" "control", "interest in", "experience" are indicators for exclusion. For structural content analysis the software package "MAXQDA Analytics Pro 2020" has been used.

\subsection{Data aggregation and computation}

Figure 3 shows the aggregation of data in order to achieve weighted relationships between Job titles ( $\mathrm{t}$ ) and work tasks (w) for IT Executives. As every job add contained one or more 


\section{$11^{\text {th }}$ International Conference on Modern Research in}

job titles firstly a decision to further use the job title which suggest the highest level in the company. The ranking was defined as followed: 1.) CIO, 2.) OIT, 3.) Leiter IT (Head/Director of IT), 4.) IT Manager. Then normalization has been executed and all job ads have been assigned to one of the job title ranks.

Every job ad now has only one title, yet there are many job ads using the same job title. The relationship is 1 to many. As many job ads have overlapping descriptions of work tasks the relationship is many to many. This results in the conclusion that the dataset as shown in Figure 3 (a), contains (among other information), titles, ads and task. This forms a unweighted tripartite graph. Assuming that a work task is either required or not in a job, a simplification can be done to focus on the relationship between titles and tasks. This results in a weighted bipartite graph between titles and tasks as shown in Figure 3(b). The count on the connection line represents the number of ads with title $t_{n}$ that require tasks $w_{m}$. For further analysis the weighted values have been converted to relative values. A similar process has been independently developed by Zhou et al. (Zhou et al. 2016)

Figure 3: Relationship concept

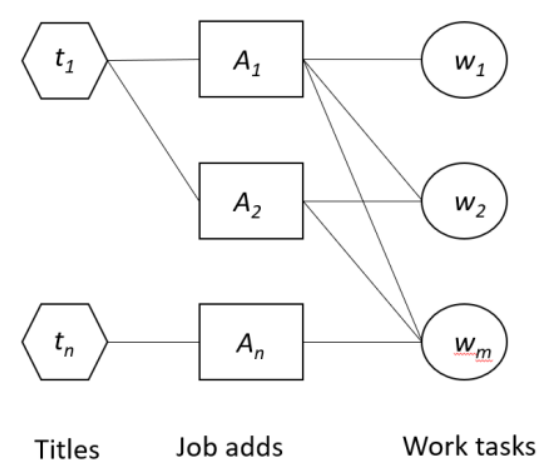

(a) Tripartite, Unweighted

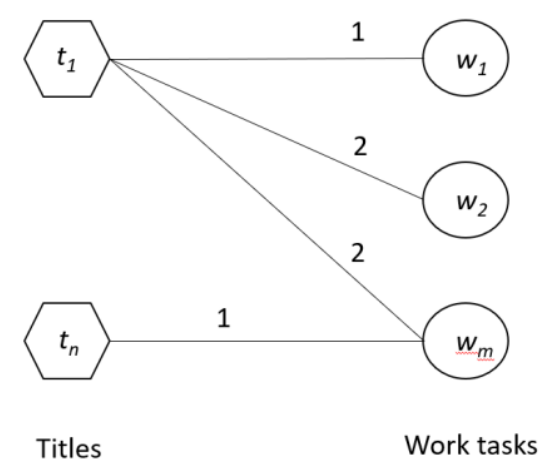

(b) Bipartite, Weighted

Source: modified from (Zhou et al. 2016)

\section{Findings}

\subsection{General Findings (not related to the hypothesis)}

The Records could be clustered into 4 Job title groups as displayed in Fig. 4 as well as the regional distribution of the job advertisements based on the structure of the federal states of Germany. The regional distribution seems to be in line with the amount of companies and organizations located in these federal states and with the population density of the states. The sample seems to be valid, yet statistical evidence should be calculated in a next step. 


\section{$11^{\text {th }}$ International Conference on Modern Research in}

\section{MANAGEMENT, ECONOMICS and ACCOUNTING}

\section{8-20 December, 2020 Oxford, United Kingdom}

Figure 4: Regional \& Job title distribution of job advertisements

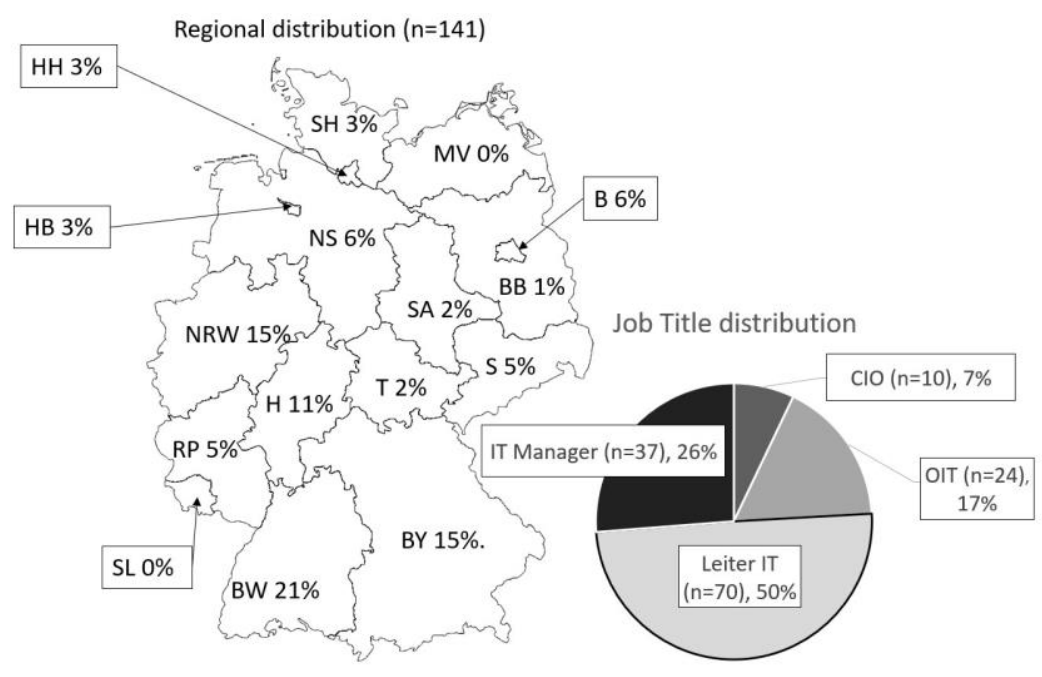

Source: author's construction

Analysis shows (Fig. 5(a)) that most job ads have been published by employers in German language. In companies with international context English language was used. These ads sometimes also used unconventional IT manager job titles summarized under other IT titles short “OIT". Figure 5(b) shows which IT titles have been used in which Sectors (all organizations which operated on the free market have been summarized under "Other"). Results show that only $54.2 \%$ of the OIT job title group are active on the free market while $46 \%$ are in the controlled healthcare environment, public (or government) institutions and non profit organizations. In the CIO job title group $10 \%$ are public employers and $20 \%$ teaching institutions.

Recommendation: Further analysis by company size in the sector "Other" should be done with the help of financial numbers about companies, be it available income statements or information from sources like company webpages or press statements. Yet this was not the focus of this research.

Figure 5.: Language and sectoral origin of the job advertisements. 
$11^{\text {th }}$ International Conference on Modern Research in

MANAGEMENT, ECONOMICS and ACCOUNTING

\section{8-20 December, 2020 Oxford, United Kingdom}

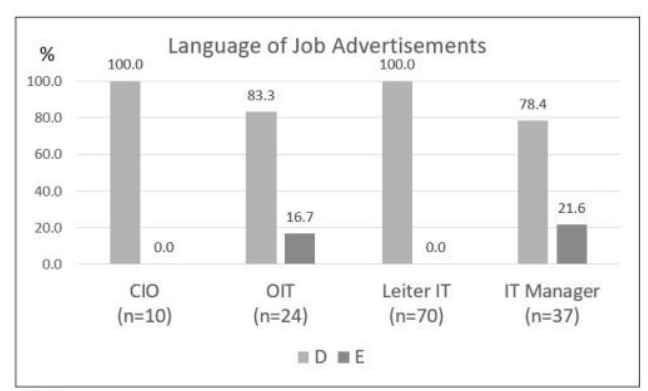

(a)

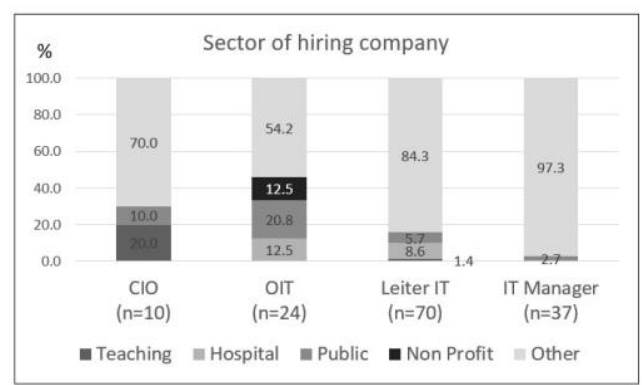

(b)

Source: author's calculations based on structured content analysis

\subsection{Findings}

Analysing the choosen variables as described in section 2.2 reviels differences between job title groups.

„Reporting structure“: Most counts for direct reporting to top management have been found in the group of OIT job titles (20.8\%) followed by the CIO job titles with $10 \%$. Leiter IT is at $7.1 \%$ followed by IT Manager $2.7 \%$.

„Leadership background“: Employers requested most and longest leadership background from candidates looking for a CIO Job title (30.0\%). (OIT 8.3\%, Leiter IT 5.7\% and IT Manager $0.0 \%$.

„Hands-on personality“ is expected from $20.0 \%$ in the CIO group, $18.9 \%$ in the IT Manager group, $14.3 \%$ in the IT Leiter Group and only $12.5 \%$ in the OIT group.

Regarding the „IT strategic orientation“ variables, following results could be found:

„IT Strategy Responsibility“: IT Leiter 34.3\%, CIO 20.0\%, OIT 16,7\% and IT Manager $16.2 \%$

In some job ads differences in the description of the IT strategy task could be observed. This lead to the assumption that every IT manager who is responsible for the Strategy at the same time is responsible for execution of it. Yet some job adds reported that candidates are only responsible for execution of availble IT strategy. This leed to following results:

„IT Strategy Execution“: Leiter IT 30.0\%, OIT 16.7\%, IT Manager 13.5\%, CIO $10 \%$.

„IT Architecture“: CIO 50.0\%, Leiter IT 10.0\%, OIT 8.3\%, IT Manager 2.7\%.

„IT Governance“: CIO 10\%, IT Manager 2.7\%, Leiter IT and OIT both $0.0 \%$

„IT Budget“: OIT 33.3\%, Leiter IT 27.1\%, IT Manager 27.0\% and CIO 20.0\%

Results are visualized in Fig. 6

Figure 6: Research results regarding personal work environment of the IT top management candidate 
$11^{\text {th }}$ International Conference on Modern Research in

MANAGEMENT, ECONOMICS and ACCOUNTING

\section{8-20 December, 2020 Oxford, United Kingdom}

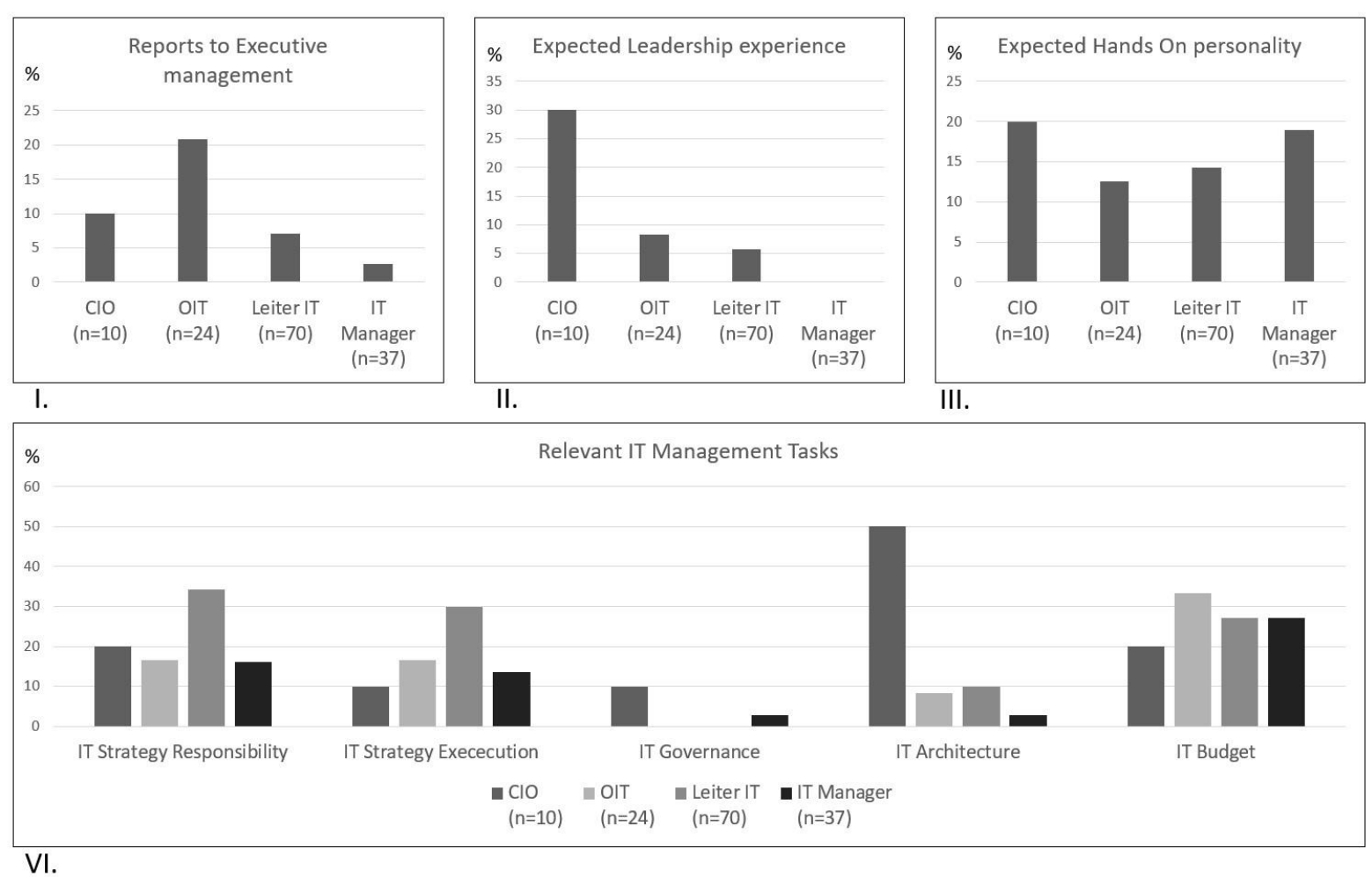

Source: author's calculations based on structured content analysis

\section{Conclusion, proposals, recommendations}

Mapping of job titles to the strategic tasks of an IT Organisation suggest that there are big differences in the role for different job titles.

The focus of CIOs is on IT Strategy responsibility, IT Architecture planning and IT Governance.

Even so, the focus of Leiter IT positions is on IT strategy responsibility, a big group only has the task to execute a given IT strategy. IT architecture might be a task for some.

IT Managers are weak on all strategic tasks, compared to the 3 other groups. IT Architecture is underrepresented which suggests that their role is utilitarian, which means their job role is more focused to supply standard infrastructure and keep the lights on.

Interestingly candidates from the OIT group are asked to keep an eye on the IT budget which might be explained by the sectors this group is active in (only $54.2 \%$ of the employers are active in the free market). For the same reason, a real comparison with the other job title groups is not meaningful. 


\title{
$11^{\text {th }}$ International Conference on Modern Research in
} MANAGEMENT, ECONOMICS and ACCOUNTING

\author{
18-20 December, 2020 Oxford, United Kingdom
}

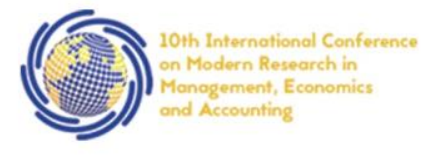

Hütter and Riedel (Hütter and Riedl 2017) suggest executive management (CEO/CFO) of companies to define the scope of the IT department, then select one or more roles. These roles could be technology provider or integration advisor, strategic supporter, business thinker, innovation driver, integration advisor or relationship manager. Using these roles to formulate the requirements of the employer in regards to tasks of an future IT Manager might be much more helpful for the candidate in deciding how strategic the offered job really is and if he therefore is the right candidate for the position.

This would change the structure of IT manager job ads completely. And one could argue that job portals could have challenges to post such offerings. Yet, this concern is not valid, as some companies already use unconventional forms of job ads to look for candidates.

The hypothesis and research question cannot clearly be answered due to the small sample size within the different job title groups. Even so a trend can be seen which is promising for statistical analysis. So, more data need to be collected and only job offerings from commercial enterprises should be included in the analysis. In addition an enrichment with financial numbers (if available), company size and industry sector would add valuable information for further analysis.

\section{References}

Ashforth, Blake E.; Kreiner, Glen E. (1999): "How Can You Do It? ": Dirty Work and the Challenge of Constructing a Positive Identity. In The Academy of Management Review 24 (3), p. 413. DOI: $10.2307 / 259134$.

Baron, James N.; Bielby, William T. (1986): The Proliferation of Job Titles in Organizations. In Administrative Science Quarterly 31 (4), p. 561. DOI: 10.2307/2392964.

Bechky, Beth A. (2006): Gaffers, Gofers, and Grips. Role-Based Coordination in Temporary Organizations. In Organization Science 17 (1), pp. 3-21. DOI: 10.1287/orsc.1050.0149.

Benlian, Alexander; Haffke, Ingmar (2016): Does mutuality matter? Examining the bilateral nature and effects of CEO-CIO mutual understanding. In The Journal of Strategic Information Systems 25 (2), pp. 104-126. DOI: 10.1016/j.jsis.2016.01.001.

Chan, Y. E.; Sabherwal, R.; Thatcher, J. B. (2006): Antecedents and outcomes of strategic IS alignment. An empirical investigation. In IEEE Trans. Eng. Manage. 53 (1), pp. 27-47. DOI: 10.1109/TEM.2005.861804.

Chen, Daniel; Preston, David (2007): Understanding CIO Role Effectiveness. The Antecedents and Consequents. In : 2007 40th Annual Hawaii International Conference on System Sciences (HICSS'07). 2007 40th Annual Hawaii International Conference on System Sciences (HICSS'07). Waikoloa, HI, USA, 03.01.2007 - 06.01.2007: IEEE, 237a-237a.

Durst, Michael (2007): Wertorientiertes Management von IT-Architekturen: Teubner.

Feeny, David F.; Edwards, Brian R.; Simpson, Keppel M. (1992): Understanding the CEO/CIO Relationship. In MIS Quarterly 16 (4), p. 435. DOI: 10.2307/249730. 


\title{
$11^{\text {th }}$ International Conference on Modern Research in
} MANAGEMENT, ECONOMICS and ACCOUNTING

\author{
18-20 December, 2020 Oxford, United Kingdom
}

Georgakakis, Dimitrios; Heyden, Mariano L.M.; Oehmichen, Jana D.R.; Ekanayake, Udari I.K. (2019): Four decades of CEO-TMT interface research. A review inspired by role theory. In The Leadership Quarterly, p. 101354. DOI: 10.1016/j.leaqua.2019.101354.

Gottschalk, P.; Taylor, N. J. (2000): Strategic management of IS/IT functions. The role of the CIO. In : Proceedings of the 33rd Annual Hawaii International Conference on System Sciences. HICSS33: Hawaii International Conference on System Sciences. Maui, HI, USA, 47 Jan. 2000: IEEE Comput. Soc, p. 10.

Hodgkinson, Stephen L. (1992): IT structures for the 1990s: organisation of IT functions in large companies. A survey. In Information \& Management 22 (3), 161-175.

Hollenbeck, John R.; Beersma, Bianca; Schouten, Maartje E. (2012): Beyond Team Types and Taxonomies. A Dimensional Scaling Conceptualization for Team Description. In The Academy of Management Review 37 (1), pp. 82-106. DOI: 10.5465/amr.2010.0181.

Hütter, Alexander; Riedl, René (2017): Chief Information Officer Role Effectiveness. Cham: Springer International Publishing.

Jones, Mary C.; Taylor, G.Stephen; Spencer, Barbara A. (1995): The CEO/CIO relationship revisited. An empirical assessment of satisfaction with IS. In Information \& Management 29 (3), pp. 123-130. DOI: 10.1016/0378-7206(95)00014-N.

Klein, Katherine J.; Ziegert, Jonathan C.; Knight, Andrew P.; Xiao, Yan (2006): Dynamic Delegation: Shared, Hierarchical, and Deindividualized Leadership in Extreme Action Teams. In Administrative Science Quarterly 51 (4), pp. 590-621. DOI: 10.2189/asqu.51.4.590.

Krcmar, Helmut (2015): Informationsmanagement. 6., überarb. Aufl. Berlin, Heidelberg: Springer Gabler.

Krotov, Vlad (2015): Bridging the CIO-CEO gap. It takes two to tango. In Business Horizons 58 (3), pp. 275-283. DOI: 10.1016/j.bushor.2015.01.001.

Lee, Jessica; Elbashir, Mohamed Z.; Mahama, Habib; Sutton, Steve G. (2014): Enablers of top management team support for integrated management control systems innovations. In International Journal of Accounting Information Systems 15 (1), pp. 1-25. DOI: 10.1016/j.accinf.2013.07.001.

Leser, Florian; Scheibehenne, Rainer; Alt, Rainer (2004): Ansatz zur Bestimmung des Architekturnutzens bei der Deutschen Telekom. In U. Baumöl, H. Österle, R. Winter, Rainer Alt, Hubert Österle (Eds.): Real-time Business. Berlin, Heidelberg: Springer Berlin Heidelberg (Business Engineering), pp. 233-253.

Li, Yan; Tan, Chuan-Hoo (2013): Matching business strategy and CIO characteristics. The impact on organizational performance. In Journal of Business Research 66 (2), pp. 248-259. DOI: 10.1016/j.jbusres.2012.07.017.

Ling, Yan; Wei, Liqun; Klimoski, Richard J.; Wu, Longzeng (2015): Benefiting from CEO's empowerment of TMTs. Does CEO-TMT dissimilarity matter? In The Leadership Quarterly 26 (6), pp. 1066-1079. DOI: 10.1016/j.leaqua.2015.07.006. 
$11^{\text {th }}$ International Conference on Modern Research in MANAGEMENT, ECONOMICS and ACCOUNTING

\author{
18-20 December, 2020 Oxford, United Kingdom
}

Liu, S. (2002): A practical framework for discussing IT infrastructure. In IT Prof. 4 (4), pp. 14-21. DOI: 10.1109/MITP.2002.1046639.

Marrone, Mauricio; Kolbe, Lutz M. (2011): Impact of IT Service Management Frameworks on the IT Organization. In Bus Inf Syst Eng 3 (1), pp. 5-18. DOI: 10.1007/s12599-010-01415 .

Mayring, Philipp (2015): Qualitative Inhaltsanalyse. Grundlagen und Techniken. 12., aktualisierte und überarb. Aufl. Weinheim: Beltz (Beltz Pädagogik).

Moher, David; Shamseer, Larissa; Clarke, Mike; Ghersi, Davina; Liberati, Alessandro; Petticrew, Mark et al. (2015): Preferred reporting items for systematic review and metaanalysis protocols (PRISMA-P) 2015 statement. In Systematic reviews 4, p. 1. DOI: 10.1186/2046-4053-4-1.

Peppard, Joe (2010): Unlocking the Performance of the Chief Information Officer (CIO). In California Management Review 52 (4), pp. 73-99. DOI: 10.1525/cmr.2010.52.4.73.

Rafaeli, Anat; Pratt, Michael G. (2012): Artifacts and organizations. Beyond mere symbolism. Mahwah, N.J.: Lawrence Erlbaum (LEA's organization and management series).

Roscher, Bjarne Erik; Brink, Norbert (2020): Tasks of IT managers: Emperical research based on job advertisements in Germany. In 3rd International Conference on Applied Research in Management, Economics and Accounting. IARMEA Paris 2020.

Schweda, Christian M.; Schmidt, Werner (2014): Leichtgewichtiges, unternehmensspezifisches IT-Management. In HMD - Praxis der Wirtschaftsinformatik 51 (5), pp. 606-615. DOI: 10.1365/s40702-014-0062-8.

Synnott, William R.; Gruber, William H. (1981): Information resource management. Opportunities and strategies for the 1980s. New York: Wiley.

Tallon, Paul P. (2014): A Process-Oriented Perspective on the Alignment of Information Technology and Business Strategy. In Journal of Management Information Systems 24 (3), pp. 227-268. DOI: 10.2753/MIS0742-1222240308.

Taylor, Joseph; Vithayathil, Joseph (2018): Who delivers the bigger bang for the buck. CMO or CIO? In The Journal of Strategic Information Systems 27 (3), pp. 207-220. DOI: 10.1016/j.jsis.2018.04.001.

Vijay Gurbaxani; Chris F. Kemerer (1990): AN AGENCY THEORY VIEW OF THE MANAGEMENT OF END-USER COMPUTING. In Proceedings of the 11th International Conference on Information Systems (ICIS), Copenhagen.

Ward, John; Peppard, Joe (2002): Strategic planning for information systems by Joe Ward \& Joe Peppard. 3rd ed. John Wiley \& Sons (Wiley Series in Information Systems).

Whitler, Kimberly A.; Boyd, D. Eric; Morgan, Neil A. (2017): The criticality of CMO-CIO alignment. In Business Horizons 60 (3), pp. 313-324. DOI: 10.1016/j.bushor.2017.01.005.

Zhou, Wenjun; Zhu, Yun; Javed, Faizan; Rahman, Mahmudur; Balaji, Janani; McNair, Matt (2016): Quantifying skill relevance to job titles. In : 2016 IEEE International Conference on 
$11^{\text {th }}$ International Conference on Modern Research in MANAGEMENT, ECONOMICS and ACCOUNTING 18-20 December, 2020 Oxford, United Kingdom

Big Data (Big Data). 2016 IEEE International Conference on Big Data (Big Data). Washington DC, USA, 05.12.2016 - 08.12.2016: IEEE, pp. 1532-1541.

www.meaconf.org info@meaconf.org 